\title{
História das Psicoterapias e da Psicanálise no Brasil: o caso do Rio de Janeiro
}

\section{History of Psychotherapies and Psychoanalysis in Brazil: the case of Rio de Janeiro}

\section{Historia de las Psicoterapias y de la Psicoanálisis en Brasil: el caso de Río de Janeiro}

\author{
Cristiana Facchinetti* \\ Fundação Oswaldo Cruz - Fiocruz, Rio de Janeiro, Rio de Janeiro, Brasil
}

\begin{abstract}
RESUMO
O presente artigo se propõe a apresentar as práticas psicoterapêuticas utilizadas pela psiquiatria brasileira no Hospício Nacional de Alienados, instituição psiquiátrica situada no Rio de Janeiro e fundada no ano de 1852. A pesquisa se debruçou sobre artigos, livros autorais e manuais médicos do Hospital Nacional de Alienados e professores da cátedra de Psiquiatria e Moléstias Mentais da Faculdade de Medicina do Rio de Janeiro. Como referencial teórico, o artigo se apoia em Chartier (1990) para indicar que, ao circular no Brasil do início do século XX, as diferentes psicoterapias tiveram que se acomodar ao contexto para poderem circular. Em especial, demonstra-se como a psicanálise foi apropriada e negociada de acordo com os repertórios disponíveis no contexto psiquiátrico local, bem como frente aos diversos interesses individuais e profissionais presentes, tendo que se adaptar para ganhar credibilidade e aceitação no ambiente da medicina mental brasileira da primeira metade do século XX. Apenas no final da década de 1950 é que se constituiria como uma disciplina independente e autônoma frente aos outros saberes psi com os quais teve que se mesclar ao longo do século.
\end{abstract}

Palavras-chave: História, Psicoterapias, Praxiterapia, Psicanálise, Brasil.

\begin{abstract}
This article proposes to present the psychotherapeutic practices used by the Brazilian psychiatry in the Hospício Nacional de Alienados, a psychiatric institution located in Rio de Janeiro and founded in the year 1852. The research focused on articles, books and medical manuals of the Hospital Nacional de Alienados and professors of the chair of Psychiatry and Mental Disorders of the Faculty of Medicine of Rio de Janeiro. As a theoretical reference, the article is based on Chartier (1990) to indicate that, when circulating in Brazil in the early twentieth century, different psychotherapies had to be accommodated to the context to be able to circulate. In particular, it is shown how psychoanalysis was appropriated and negotiated according to the repertoires available in the local psychiatric context, as well as to the various individual and professional interests present, having to adapt to gain credibility and acceptance in the Brazilian mental medicine environment of
\end{abstract}


the first half of the twentieth century. Only in the late 1950s would it be constituted as an independent and autonomous discipline against the other psychological knowledge with which it had to blend throughout the century.

Keywords: History, Psychotherapies, Labor therapy, Psychoanalysis, Brazil.

\section{RESUMEN}

El presente artículo se propone presentar las prácticas psicoterapéuticas utilizadas por la psiquiatría brasileña en el Hospicio Nacional de Alienados, institución psiquiátrica situada en Rio de Janeiro y fundada en el año 1852. La investigación se centró en artículos, libros de autor y manuales de médicos del Hospital Nacional de Alienados y de profesores de la cátedra de Psiquiatría y Molestias Mentales de la Facultad de Medicina de Rio de Janeiro. Como referente teórico, el artículo se apoya en Chartier (1990) para indicar que, al circular en Brasil desde el inicio del siglo XX, las diferentes psicoterapias tuvieron que acomodarse al contexto local para poder circular. En particular, se demuestra cómo el psicoanálisis fue apropiado y negociado de acuerdo a los repertorios disponibles en el contexto psiquiátrico local, así como frente a los diversos intereses individuales y profesionales presentes, teniendo que adaptarse para ganar credibilidad y aceptación en el ambiente de la medicina mental brasileña de la primera mitad del siglo XX. Sólo a finales de la década de 1950 se constituiría como una disciplina independiente y autónoma frente a los otros saberes psi con los que tuvo que mezclarse a lo largo del siglo.

Palabras clave: Historia, Psicoterapias, Praxiterapia, Psicoanálisis, Brasil.

\section{História das Psicoterapias e da Psicanálise no Brasil: o caso do Rio de Janeiro}

Tanto como hoje em dia, as psicoterapias foram constituídas como instrumentos capazes de produzir efeitos curativos sobre 0 psiquismo, excluindo, prevenindo ou inibindo impulsos indesejáveis decorrentes da condição dos indivíduos mentalmente enfermos ou sob risco de adoecimento. Entretanto, como se pretende demonstrar neste artigo, tais práticas são revestidas por historicidade e contingências, o que produz modulações variadas no sentido que ganham nos diferentes contextos históricos, de acordo com as teorias psiquiátricas em voga e sua leitura acerca da subjetividade, liberdade e vontade humanas. É a partir de tal compreensão que este artigo se propõe a apresentar as práticas psicoterapêuticas utilizadas pela psiquiatria brasileira na primeira metade do século XX.

A metodologia priorizou o levantamento de fontes bibliográficas primárias cujos autores eram médicos do Hospital Nacional de Alienados ${ }^{1}$ e professores da cátedra de Psiquiatria e Moléstias Mentais da Faculdade de Medicina do Rio de Janeiro. Em especial, trabalha-se aqui com artigos e livros autorais e manuais voltados para o treinamento clínico dos estudantes do último ano de medicina, quando passavam pelo Pavilhão de Observações, ${ }^{2}$ a porta de entrada para a internação no Hospício Nacional. 
Como referencial teórico, o artigo se apoia em Chartier (1990), com quem busca indicar que, ao circular em diferentes culturas, o conhecimento científico é apropriado e negociado de acordo com os repertórios disponíveis nos contextos locais, bem como frente aos diversos interesses individuais e profissionais presentes em um dado contexto.

\section{Dos discursos às terapêuticas no Hospício Nacional}

A cátedra de Psiquiatria e Moléstias Mentais havia sido criada em 1881 e a partir de então é possível verificar, por meio da análise dos títulos das teses de conclusão do curso nas Faculdades de Medicina do Rio de Janeiro e da Bahia, ${ }^{3}$ que 0 interesse pelas psicoterapias cresceu.

Esse ethos terapêutico (Cushman, 1995, p. 63) constituiu-se inicialmente em torno da histeria e da (auto)hipnose principalmente, com debates sobre sua psicopatologia, descrita comumente a partir da psiquiatria de língua francesa, como acontecia em toda a América Latina ao longo do XIX (Klappenbach, 2006, 2013), ${ }^{4}$ ainda que houvesse a circulação de teorias de outras nacionalidades no circuito médico carioca (Ribeiro, 2016). Mas especialmente depois de 1870, com as reformas no ensino médico no país em busca de objetividade e cientificidade, a psiquiatria alemã começou ganhar mais terreno (Muñoz, 2018).

Sob o peso da influência francesa e de sua concepção iluminista do ser humano, o tratamento psicoterapêutico das moléstias mentais no Hospício Nacional de Alienados consistia quase sempre na ação sobre a consciência, principalmente por meio da persuasão, do isolamento, do repouso, do tratamento moral e da correção psicológica (Pinel, 1800-1801; Nina-Rodrigues, 2004), além da hipnose charcotiana (Roxo, 1913). Mas com os novos recursos teóricos oferecidos junto à cátedra de psiquiatria ${ }^{5}$ e as pesquisas levadas a cabo no asilo ${ }^{6}$, novas modalidades terapêuticas foram postas à disposição dos médicos.

Em grande parte, a difusão do modelo kraepeliano no Brasil e suas exigências de cientificidade, assim como sua concepção fisicalista e determinista do ser humano, difundiu uma série de terapêuticas que se propunham agir diretamente sobre o organismo, como foi o caso da clinoterapia, da eletroterapia estimulante ou convulsionante, dos serviços cinesioterápicos (de movimento) e hidroterápicos e de balneoterapia, bem como de uma ampla diversidade de tratamento químico (Facchinetti \& J acó-Vilela, 2019).

Mas outra tecnologia cada vez mais frequentemente citada nos relatos clínicos e manuais de psiquiatria era a psicoterapia, tratamento ao qual "se emprega a acção psychica como agente 
therapeutico" "com fim curativo" (Medeiros, s.d., p.15). A partir da década de 1920, especialmente, assistiu-se a diversos esforços para a sua sistematização racional por causada crescente importância que ela ia adquirindo para toda a área médica e mesmo para a cultura em geral (Pires, 1951, p.140).

\section{Psicoterapias no Distrito Federal}

Mauricio Campos de Medeiros (1885-1966), titular da cadeira de psiquiatria da Universidade do Brasil a partir de 1945 e que havia sido responsável pelo primeiro laboratório de psicologia experimental do Hospício Nacional (Medeiros, 1908), buscou descrever neste período a diversidade de tipos psicoterápicos em circulação no Distrito Federal. Em uma obra voltada exclusivamente para as psicoterapias, o médico - que se tornaria, em 1955, ministro da saúde do governo de Nereu Ramos e a seguir do de Juscelino Kubitschek -, descreveu as psicoterapias "empíricas" e as científicas, considerando ambas eficazes.

Com relação às empíricas, Medeiros nos informa que estas englobariam as religiões, o curandeirismo e o mesmerismo, e afetariam principalmente o campo da moral e da (auto) sugestão curativa, tendo como desvantagem não serem passíveis de controle (Medeiros, s.d., p. 63). Já as psicoterapias "científicas", tecnologias produzidas a serviço das ciências psiquiátricas e psicológicas do período, variavam de acordo com o elemento psicológico que pretendiam afetar (idem).

Dessas modalidades, talvez a mais importante para o Serviço Nacional de Doenças Mentais ${ }^{7}$ era a praxiterapia, valorizada então como capaz de oferecer melhoramentos de grande utilidade para quase todos os quadros psicopatológicos (Pires, 1932; Garcia, 1946). O investimento nessa terapêutica remonta a Pinel (1800-1801), e portanto, esteve presente também no asilo brasileiro desde sua fundação, em 1852 (Ribeiro, 2016). Mas a partir de 1903, para implementar maior eficiência a essa tecnologia, o recém-empossado diretor do asilo, Juliano Moreira ${ }^{8}$, efetuou diversas melhorias no Hospício Nacional de Alienados: reformou as bibliotecas das seções masculinas e reorganizou o Pavilhão Seabra, exclusivamente voltado para a laborterapia, com oficinas de carpintaria, sapataria, pintura, as oficinas de tipografia, etc. para pacientes não pagantes (Facchinetti \& Muñoz, 2013) Essa modalidade psicoterapêutica ganhou ainda maior alcance no país a partir de 1915 (Araújo e Vilela, 2018, p.4). Nesse processo, três décadas depois, a praxiterapia havia se tornado a principal tecnologia das políticas voltadas para os doentes mentais de todo o país, então denominada como método de tratamento psíquico por meio do trabalho. Encontramos referência a essa psicoterapia 
especialmente nos hospitais colônia que se espalhavam pelo país, onde aparece como sinônimo de "laboriterapia", "ergasioterapia" e "terapêutica ocupacional" (Garcia, 1946, p. 500).

E por que a praxiterapia era considerada uma prática psicológica de alcance curativo? Considerava-se que o trabalho, como atividade física e psíquica, era capaz de facilitar a reeducação e readaptação ao meio social, desviando as atividades psíquicas do doente para fins úteis. O Prof. José Alves Garcia, que em 1946 era docente e chefe da divisão de pesquisa do Instituto de Psiquiatria da Universidade do Brasil, além de professor interino da Clínica Psiquiátrica da Escola de Medicina e Cirurgia do Rio de Janeiro, apontava que a psicoterapia era útil aos internos das colônias, porque era capaz de operar grandes mudanças: "desperta-lhes o interesse pelo ambiente e o desejo de viver, a vontade de curar-se. E se a cura não for possível, ao menos uma vida nosocomial mais suportável". (Garcia, 1946, p. 500-501).

Mas para ser de fato científica, era preciso associar a praxiterapia referenciais teóricos e metodológicos capazes de afirmar sua eficácia e controlar seus resultados. Para o professor, a praxiterapia deveria ser utilizada de acordo com a metodologia de Hernmann Simon (1929) e Franz Eschle (1909), que propunham a terapia ativa e sistemática de trabalho individualizado como forma de readaptar, regenerar e reeducar os sujeitos internos dos asilos para a vida externa, associando tais atividades à sugestão, persuasão e incitação de recompensas e regalias, para que fosse capaz de produzir o esperado resultado psicoterápico. Além disso, o médico recomendava a manutenção da ordem e da disciplina como instrumentos para a reeducação, capazes de por si só produzirem sentimento ético e suscitarem domínio de si mesmo ao doente, o que ocorreria como "efeito de correção psicagógica" (Garcia, 1946, p. 501-502).

Nesse processo, era indispensável adequar a atividade ao doente, já que haveria tarefas de diferentes graus de complexidade, desde as de primeiro grau (ocupação simples, sem exigência de autonomia ou atenção - por exemplo, carregar objetos junto a outra pessoa); até trabalhos de quarto grau, que exigiam dos internos condições normais de atividade (Garcia, 1946, p. 503).

Outra técnica psicoterápica utilizada fora uma terapêutica comumente utilizada no século anterior e que continuavam a ter seguidores: a hipnose. Franz Anton Mesmer (1734-1815) e Jean-Martin Charcot (1825-1893) eram ainda acionados como autoridade para demonstrar a força da sugestão instrumental e do ambiente no aparelho psíquico do doente (Roxo, 1938). Segundo Mauricio de Medeiros, essa psicoterapia deveria ser associada ao isolamento, repouso e tratamento moral (Medeiros, s.d, p. 88-96). Esse procedimento psicoterápico consistia em inocular no psiquismo do doente ideias, sentimentos, emoções ou qualquer outro elemento moral por 
sugestão, não permitindo a este qualquer crítica ou julgamento. Objetivava criar um automatismo disciplinado, em um processo de reeducação e de readaptação ao trabalho intelectual. Como é possível perceber, esse modelo ecoava também o alienismo de Pinel, em seu Tratado de 1800 (2007) e estivera presente na instituição durante todo o período de sua existência (Ribeiro, 2016).

Mas a tecnologia psicoterápica não se restringia a essas práticas, ganhando ainda novas nuances e recursos. A psicanálise passou a comparecer no asilo pelo menos a partir de 1914, quando dois dos principais médicos da instituição, os doutores Juliano Moreira e Antonio Austregésilo, se juntaram ao residente Genserico Pinto e passaram a utilizá-la em alguns pacientes pensionistas, de classe mais abastada (Facchinetti, 2012).

A partir da década de 1920, passou a ser creditado à psicanálise o poder de auxiliar os psiquiatras em um projeto profilático através da educação, principalmente com as crianças, evitando assim o surgimento de futuros infratores e/ou desviantes (Castro, 2015). Além disso, ela passou a ser compreendida como instrumento auxiliar no conhecimento maior sobre o meio e a sociedade em que os médicos mentais pretendiam intervir, trazendo a possibilidade de compreender a psicologia coletiva do homem brasileiro, seus "totens e tabus" e suas características mais peculiares (Facchinetti, 2012).

Enquanto isso, no antigo asilo, outros médicos passaram a utilizar os métodos de associação livre e de interpretação dos sonhos (Roxo, 1938). Depois de um período de resistências, especialmente da parte dos médicos de base teórica francesa, o "freudismo" paulatinamente começou a ganhar espaço mesmo junto aos organicistas, tanto no Brasil como internacionalmente (Cerqueira, 2014). Vale dizer, mesmo Kretschmer, responsável por uma psicoterapia das constituições, voltado para permitir ao paciente aceitar "tornar-se aquilo que é ",isto é, aceitar suas limitações e inclinações advindas de sua constituição orgânica (Dias, 2015), reconhecia a importância da psicanálise na formação de uma personalidade "normal", dentro de um determinado "espaço vital" (Kehl, 1941; Pires, 1951, p. 139).

Isso implica dizer, portanto, que não apenas as psiquiatrias de cunho psicodinâmico, como a psiquiatria de Eugen Bleuler (1857-1939)que sofria certa influencia direta da psicanálise, mas também aquelas que compreendiam o mental como tendo uma base principalmente orgânica e hereditária passaram a apostar na íntima relação entre o sistema nervoso e a vida vegetativa, ampliando em muito o campo de inflexão entre o orgânico e o psíquico (Medeiros, s/d). Eugenistas como Renato Kehl (1889-1974), por exemplo, passaram a aceitar e mesmo indicar a prática psicoterapêutica, por compreender que, por meio dela, o indivíduo poderia se tornar capaz de modular ou disfarçar certas tendências mórbidas de sua constituição (Kehl, 1941), permitindo a vida em sociedade. Deste modo, o número de 
psiquiatras que passaram a creditar alguma importância ao processo psicanalítico só cresceu.

A psicanálise era então compreendida como "uma nova psicologia" elaborada por Freud, "baseada no inconsciente dinâmico". Diferentemente das outras anteriormente apresentadas, que trabalhavam com a consciência e com o automatismo psíquico, esta tinha como aplicação terapêutica "a produção da projeção do inconsciente sobre a consciência" (Medeiros, s.d, p. 98). Mas vale dizer para aqueles que imaginam que a psicanálise sempre foi lida de maneira uníssona, que essa compreensão permitiu aos médicos, ao longo da década de 1930 e 1940 articular de maneira linear a psiquiatria - que tratava do distúrbio orgânico - com a psicanálise, frequentemente compreendida como ferramenta auxiliar no processo de recuperação do alienado à realidade e de readaptação dos psicopatas (Facchinetti, 2012).

Com tal articulação, a psicoterapia de base psicanalítica ganhou cada vez mais adeptos em todo o país, acompanhando uma tendência mundial. Considerada por alguns médicos como benéfica apenas para uma elite de nevróticos, seu uso vinha se tornando popular, ampliando a psicanálise como prática e como método de pesquisa e sistema filosófico predominante no campo psiquiátrico. Júlio PortoCarrero (1929, p. 14) é um bom exemplo desse entusiasmo de primeira hora, e se autonomeava como psicanalista, ao mesmo tempo em que apostava na eugenia. Por outro lado, havia aqueles como Wilhelm Weygandt, para quem a mania interpretativa da psicanálise havia se tornado "uma epidemia" (Gay, 1989, p. 185). Assim também pensavam alguns psiquiatras locais, como Garcia, para quem seu uso abusivo feria "a boa ética e os foros da medicina, além de ser prejudicial em muitos casos" (Garcia, 1946).

No Instituto de Psiquiatria, recém fundado em 1938, além de Freud, circulavam psicanalistas como Alfred Adler e Karl Gustav Jung, além do psiquiatra Eugen Bleuler (Garcia, 1946, p. 508-511). Novos autores também começavam a chamar atenção, com Franz Alexander e Victor Von Weiszacker, Melanie Klein e Anna Freud, denominados então de neofreudianos (Pires, 1951, p.139-140).

Os manuais de psiquiatria indicavam que a psicanálise deveria ser aplicada individualmente. O paciente deveria ficar deitado em decúbito dorsal num quarto, com o médico por detrás para facilitar a associação livre, evitando as barreiras da censura. A prática era considerada tão experimental quanto o exame feito por uma bacteriologista ou pelo exame elétrico:

um sorriso, um rubor, movimento de membros, um suspiro tem para o analista significação. O que guia a análise é a emoção do analisado; quando as associações resvalam no complexo, em que se toca o problema vital, dá-se a explosão afetiva, uma 
intuição final da coisa oculta, livrando o doente do tormento e dando em troca satisfação e alivio (Garcia, 1946, p. 509-510).

Além do trabalho por associação, o sujeito em análise deveria anotar os sonhos ao acordar. Deste modo, permitiria ao seu analista a sua exegese atrás dos símbolos oníricos, que seriam a expressão dos sentimentos recalcados e semelhantes às ideias psicogênicas.

Mas havia as dificuldades com a técnica e essas diziam principalmente a quantidade de tempo que cada terapia necessitava. Muitas vezes, ao invés de aguardar a "confissão" do paciente (Garcia, 1946, p. 511), os médicos, apoiados em Jung e Bleuler, apresentavam a ele palavras indutoras para produzir reação (o teste de associação de palavras de Jung), e a duração dos atos de fala eram medidos por um cronógrafo. Outros estimulavam o acesso ao inconsciente através da administração de um "hipnótico brando, uma pequena dose de escopolamina ou por meio da eterização ou do somnifene", entre outros. (Garcia, 1946, p. 511-512).

Como complemento às dificuldades da técnica, recomendava-se ao médico estar atento contra o "perigoso" processo de transferência, frente a qual só estaria seguro aquele que tivesse "perfeita formação moral e absoluto domínio de si" (Garcia, 1946, p. 512). Caso contrário, a transferência e a contratransferência levariam a consequências desastrosas, seja pela produção de desordens mentais de conteúdo erótico e perseguidor, seja pelo aumento da ansiedade patológica do paciente após um processo mal conduzido. Finalmente, alguns autores consideravam que a psicanálise poderia ser extremamente contraproducente. Garcia, por exemplo, considerava que se a psicanálise fosse utilizada no tratamento de indivíduos portadores de doenças evolutivas (como no caso da esquizofrenia ou da encefalia letárgica), causaria grave prejuízo ao curso ulterior da moléstia.

Mas apesar das resistências de diferentes médicos, e das dificuldades de aplicação terapêutica, ao final da década de 1940, a psicanálise já havia impregnado boa parte das técnicas psicoterapêuticas locais. $O$ problema que se colocava como obstáculo para sua difusão na assistência pública era ainda o tempo.

Os médicos passaram então a buscar meios menos ortodoxos de tratamento, que dessem maior flexibilidade para a técnica, com maior ganho de tempo e eficácia, de modo a ampliar o uso da psicanálise para todos os "setores da medicina (e da cultura em geral)" (Pires, 1951, p. 139).

Visava-se também levar a psicanálise para "camadas mais extensas e economicamente menos aquinhoadas" (Pires, 1951, p. 139) da população. Assim, o maior desafio era viabilizar uma psicanálise ambulatorial, que permitisse a cada médico atender dezenas de doentes em um curto espaço de tempo e, ao mesmo tem pudesse 
manter a qualidade das curas terapêuticas, que se viam ameaçadas pelas mudanças de setting (Pires, 1951, p. 144; Garcia, 1946, p. 513-514).

\section{Considerações finais}

Compreende-se que a análise histórica das tecnologias psicoterapêuticas permite trazer mais luz para o projeto de nação que - Estado brasileiro estava buscando implementar no início do século XX no Brasil, com importantes consequências para os modelos de cientificidade locais. As psicoterapias, que nesse período tinham como objetivo transformar indivíduos doentes e asilados em cidadãos normais, capazes de contribuir para o progresso da nação, dão visibilidade para os imaginários sociais acerca da anormalidade e para os parâmetros de tratamento e cura, demonstrando como são históricos e contingentes os sentidos que ganham essas tecnologias e como as noções de normalidade e anormalidade dependem de um longo processo de negociação entre os diversos atores envolvidos com a saúde mental dos brasileiros. Permite, além disso, dar visibilidade para certas facetas dos projetos de governo propostos pela república velha (1890-1929), pelo golpe de 1930 (1930-37) e pelo estado de exceção que caracterizou o Estado Novo (1937-1944), bem como suas agendas de organização social e de administração em processos conflituosos e ambivalentes, marcados por tensões e negociações nos limites disciplinares de diferentes autoridades e saberes.

Esperamos ter demonstrado ao longo deste artigo que, no período em questão, as psicoterapias de base analítica foram ganhando força apesar das resistências de atores e das dificuldades do método, induzindo regimes de pensamento de base psicogênica mesmo em um ambiente fortemente apoiado nas diversas teorias organicistas do período.

Como resultado, a psicanálise ganhou força, se constituindo como um dos principais métodos auxiliares do psiquiatra no país, Tal destaque permitiu que ela fosse se destacando paulatinamente dos outros saberes que a atravessavam. É curioso constatar que para que a psicanálise pudesse se tornar um saber próprio e autônomo, destacado das disputas sobre quem poderia falar com propriedade sobre o sujeito em sofrimento psicológico ao final da década de 1950,com a formação das primeiras sociedades psicanalíticas locais, ela tivesse que atravessar um longo período de negociações com as diversas teorias médico-mentais sobre o humano, se articulando de maneira dependente para ser aceita como parte do repertório científico local até ganhar espaço para se constituir como uma disciplina independente. Nesse percurso, foi atravessada por 
instituições, saberes e atores que a constituíram de maneira particular e vinculada ao contexto histórico e político de sua circulação.

\section{Referências}

Araújo, J. H. Q., \& Jacó-Vilela, A. M. (2018). The experience of art at the Juliano Moreira Colony in the 1950s. História, Ciências, Saúde - Manguinhos, 25(2), 1-14. doi:10.1590/s010459702018000200002

Facchinetti, C., Cupello, P. E., \& Evangelista, D. F. (2010). Arquivos Brasileiros de Psiquiatria, Neurologia e Ciências Afins: uma fonte com muita história. História, Ciências, Saúde Manguinhos, 17(supl. 2), 527-535. doi:10.1590/S010459702010000600015

Facchinetti, C. (2012). Psicanálise para Brasileiros: História de sua Circulação e sua Apropriação No Entre-Guerras. Culturas Psi, 0, 45-62. Recuperado

https://www.arca.fiocruz.br/handle/icict/30012

Facchinetti, C., \& Munoz, P. F. N. (2013). Emil Kraepelin na ciência psiquiátrica do Rio de Janeiro, 1903-1933. História, Ciências, Saúde - Manguinhos, 20(1), 239-262. doi:10.1590/S010459702013000100013

Facchinetti, C., \& Jacó-Vilela, A. M. (2019). Psychology in Brazilian Assistance to the Insane: first half of the 20th century. Universitas Psychologica. Trabalho não publicado.

Castro, R. D. (2015). A sublimação do id primitivo em ego civilizado: o projeto dos psiquiatras-psicanalistas para civilizar o país (1926-1944). Jundiaí: Paco Editorial.

Centofanti, R. (2001). Radecki, W. In R. H. F. Campos (Org.), Dicionário Biográfico da Psicologia no Brasil. Rio de Janeiro, I mago.

Cerqueira, E. C. B. (2014). A Sociedade Brasileira de Neurologia, Psiquiatria e Medicina Legal: debates sobre ciência e assistência psiquiátrica (1907-1933) (Dissertação de Mestrado). Casa de Oswaldo Cruz/Fiocruz, Rio de Janeiro, RJ.

Chartier, R. (1990). A história cultural: entre práticas e representações. Rio de Janeiro: Difel/Bertrand Brasil.

Cushman, P. (1995) Constructing the self, constructing America: a cultural history of psychoterapy. Reading, Massassuchetts: Addison-Wesley.

Dias, A. A. T. (2015). Arquivos de Ciências, Crimes e loucuras: Heitor Carrilho e o debate criminológico do Rio de Janeiro entre as décadas de 1920 E 1940 (Tese de Doutorado). Fundação Oswaldo Cruz, Rio de Janeiro, RJ . 
Eschle, F. C. R. (1909). Die Erziehungzur Arbeitunddurch Arbeitalssouveränes Mittel der psychischen Therapie. Zeitschriftfür Psychotherapie und medizinische Psychologie, 1, 15-42.

Garcia, J. A. (1946). Compêndio de psiquiatria (2a ed.). Rio de Janeiro: A Casa do Livro.

Gay, P. (1989). Freud. Uma vida para o nosso tempo. São Paulo: Cia das Letras, 1989.

Kehl, R. (1941). A psicologia da personalidade - guia de orientação psicológica. Rio de Janeiro, Francisco Alves.

Klappenbach, H. (2006). Recepção da Psicologia Alemã e Francesa pela J ovem Psicologia Argentina. Mnemosine, 2(1), 75-86.

Mathias, C. M. (2017). O Pavilhão de Observação na psiquiatria do Distrito Federal: a gestão de Henrique Roxo (1921-1945) (Dissertação de Mestrado). Casa de Oswaldo Cruz/Fiocruz, Rio de Janeiro, RJ .

Medeiros, M. (1908). A questão dos métodos em psicologia. Archivos Brasileiros de Psychiatria, Neurologia e Medicina Legal, (1-2), 23-51.

Medeiros, M. (s.d.). Psychoterapia: Conceito atual: Theoria e prática. Rio de Janeiro: Guanabara/Waissman Koogan.

Muñoz, P. (2018). Clínica, laboratório e eugenia: uma história transnacional das relações Brasil-Alemanha. Rio de Janeiro: Fiocruz/Puc-Rio.

Nina-Rodrigues, R. (2004). A paranóia nos negros: estudo clínico e médico-legal (1903): Parte I. Revista Latinoamericana de Psicopatologia Fundamental, 7(2), 161-178.

Pinel, P. (1800-1801). Tratado médico filosófico sobre a alienação mental ou a mania. Porto Alegre: UFGRS, 2007.

Pires, N. (1951). Relatório sobre o I Congresso Internacional de Psiquiatria. Neurobiologia, 14(2), 134-145.

Porto-Carrero, J. P. (1929). Ensaios de psicanálise. Rio de Janeiro: Flores e Mano.

Ribeiro, D. C. (2016). Os sentidos do Hospício de Pedro II: dinâmicas sociais na constituição da psiquiatria brasileira (1842-1889). (Tese de Doutorado). Casa de Oswaldo Cruz/Fiocruz, Rio de Janeiro, RJ .

Roxo, H. B. B. (1913). Doenças Mentais e Nervosas. Brasil-Médico, 27(46), 503-505.

Roxo, H. B. B. (1938). Manual de Psychiatria. Rio de Janeiro: Livraria Francisco Alves.

Simon, H. (1929). A ktivere Krankenbehandlung in der Irrenanstalt. Berlin, Leipzig: DeGruyter. 


\section{Endereço para correspondência \\ Cristiana Facchinetti}

Fundação Oswaldo Cruz

Centro de Documentação e História da Saúde (CDHS) - sala 335

Av. Brasil, 4365, Manguinhos, CEP 21040-900, Rio de Janeiro, RJ, Brasil

Endereço eletrônico: cristiana.facchinetti@fiocruz.br

Recebido em: 20/12/2018

Aceito em: 08/02/2019

\section{Notas}

* Psicanalista, com mestrado e doutorado em teoria psicanalítica (UFRJ) e pósdoutoramento em história das ciências (Fiocruz). É professora do Programa de PósGraduação em História das Ciências e da Saúde da Casa de Oswaldo Cruz, da Fiocruz / Rio de J aneiro e do Programa de Mestrado Profissional em Atenção Psicossocial do Instituto de Psiquiatria (IPUB / UFRJ). Também é professora permanente no Programa de PósGraduação em Psicologia, menção teoria e clínica psicanalíticas, na Universidade Diego Portales, em Santiago do Chile.

1 A instituição foi chamada de Hospício de Pedro II durante o Império; com a proclamação da República, passou a denominar-se Hospício Nacional de Alienados e, em 1911, ganhou o nome de Hospital Nacional de Alienados. Em 1927 foi renomeada como Hospital Nacional de Psicopatas. (Facchinetti, Cupello, \& Evangelista, 2010).

2 O Pavilhão de Observação, criado em 1884, transformou-se posteriormente em um instituto de pesquisas independente, o Instituto de Psiquiatria da Universidade do Brasil (IPUB), hoje pertencente à Universidade Federal do Rio de Janeiro. Para essa história, ver Mathias, 2017.

${ }^{3}$ Os dois primeiros cursos superiores de medicina foram criados na Bahia e no Rio de Janeiro, após a chegada de João VI para o país. As teses eram produções de seus alunos ao final do curso de graduação.

${ }^{4}$ Nas teses voltadas para as psicoterapias, as referências mais frequentes nesse final do XIX eram Philippe Pinel (1745-1826), Jean-Étienne Esquirol (1772-1840), Valentin Magnan (1835-1916), Jean-Martin Charcot (1825-1893), Pierre Janet (1859-1947) e Hippolyte Bernheim (1840-1919) (c.f. Ribeiro, 1886; Fajardo J unior, 1889)

5 Já as referências germanófonas mais frequentes eram Theodor Hermann Meynert (1833-1891), Emil Kraepelin (1856-1926), Eugen Bleuler (1857-1939) e Sigmund Freud (1856-1939)

${ }^{6}$ Para as pesquisas desenvolvidas no Hospício Nacional, ver Muñoz, 2018.

$7 \mathrm{O}$ decreto 206, de 1890, estabeleceu a Assistência Médica e Legal de Alienados (1890-1927), que servia apenas ao Distrito Federal. Em 1927, foi renomeada para Assistência a Psicopatas (1927-1941), passando a incluir não apenas os alienados, mas também aqueles em risco de desenvolver distúrbios psíquicos. A busca de nacionalização de práticas e modelos ganhou maior centralidade e sistematização a partir de 1941, com a sua reestruturação para Serviço Nacional de Doenças Mentais (1941-1970) (Facchinetti \& J acó-Vilela, 2019).

${ }^{8}$ Sobre Juliano Moreira, ver (Facchinetti \& Muñoz, 2013).

Este trabalho é um dos produtos que resultaram de uma pesquisa sobre a história do Asilo Nacional dos Alienados (1841-1944), que recebeu apoio do PROEP / CNPq / Fiocruz entre os anos de 2015 e 2018.

Este artigo de revista Estudos e Pesquisas em Psicologia é licenciado sob uma Licença Creative Commons Atribuição-Não Comercial 3.0 Não Adaptada. 